\title{
Fluid resuscitation in trauma
}

\author{
A. Rudra, S. Chatterjee*, S. Sengupta, R. Wankhade, S. Sirohia, T. Das
}

Appropriate fluid replacement is an essential component of trauma fluid resuscitation. Once hemorrhage is controlled, restoration of normovolemia is a priority. In the presence of uncontrolled haemorrhage, aggressive fluid management may be harmful. The crystalloid-colloid debate continues but existing clinical practice is more likely to reflect local biases rather than evidence based medicine. Colloids vary substantially in their pharmacology and pharmacokinetics, and the experimental finding based on one colloid cannot be extrapolated reliably to another. In the initial stages of trauma resuscitation the precise fluid used is probably not important as long as an appropriate volume is given. Later, when the microcirculation is 'leaky', there may be some advantages to high or medium weight colloids such as hydroxyethyl starch. Hypertonic saline solutions may have some benefit in patients with head injuries. A number of hemoglobin solutions are under development, but one of the most promising of these has been withdrawn recently. It is highly likely that at least one of these solutions will eventually become routine therapy for trauma patient resuscitation. In the meantime, contrary to traditional teaching, recent data suggest that restrictive strategy of red cell transfusion may improve outcome in some critically ill patients.
\end{abstract}

Key words: Fluid therapy, resuscitation, body fluids, water-electrolyte balance, trauma

Since uncontrolled hemorrhage is one of the leading causes of early death after trauma, ${ }^{[1,2]}$ the treatment of these casualties at the site of the injury or during transportation to the hospital remains an important issue. This is particularly true where the bleeding source cannot be controlled without surgery or interventional radiology. ${ }^{[3]}$ Therefore, after ensuring an adequate airway, oxygenation and ventilation, the focus for resuscitation of the severely injured patient switches to approach to appropriate and effective fluid replacement to reverse hemorrhagic shock and to restore perfusion to vital organs. ${ }^{[4]}$ Each decade has brought improvements in our understanding of shock following trauma. With more understanding of the underlying mechanisms, we have been able to define more

\section{From:}

Consultant Anaesthesiologists at Apollo Gleneagles Hospital, *Medical College and Hospital, Kolkata, India

Correspondence:

Dr. A. Rudra, 1, Shibnarayan Das Lane, Kolkata - 700 006, India. E-mail: sumanc_24@yahoo.co.in clearly optimal resuscitation strategies.

\section{Historical Perspective}

Blalock $^{[5]}$ believed that shock following trauma was caused by an exhaustion of the vasomotor centre because of over stimulation. He further demonstrated in canine experiments that plasma fluid could escape into injured tissue in volumes sufficient to produce hypotension. Cannon et $a^{\left[{ }^{[6]}\right.}$ warned, "Injection of a fluid that will increase blood pressure has dangers in itself. Hemorrhage in a case of shock may not have occurred to a marked degree because pressure has been too low to overcome the obstacle offered by a clot. If the pressure is raised before checking the bleeding, blood that is sorely needed may be lost".

\section{Physiology ${ }^{[7]}$}

Shock is an imbalance in the oxygen supply to tissues relative to the needs of the tissues. Loss of intravascular 
volume causes increased vascular tone. Blood flow is redistributed among the organ systems of the body and perfusion to the heart and brain is maintained at the expense of cutaneous, splanchnic and renal vascular beds. Intravascular volume deficits cause increase in sympathetic tone. Capillary hydrostatic pressure is decreased and the extracellular fluid is depleted as transcapillary refill occurs. Acidosis initially facilitates the unloading of oxygen to the tissues and urine output is diminished as water and sodium are retained. Catecholamine levels are increased to increase cardiac output and blood pressure. Release of prostaglandins cause local vasodilatation, whereas thromboxane $A_{2}$ release, cause vasoconstriction. Platelet-activating factor causes coronary vasoconstriction and increases platelet aggregation. ${ }^{[8]}$

\section{Resuscitation Fluid}

Blood: Few would argue that the best resuscitation fluid is blood. It offers the advantages of volume expansion and also transports oxygen. It also remains in the intravascular space for prolonged periods. There are, however, many disadvantages to blood as a resuscitation fluid. It must be cross-matched, which requires a specimen from the patient and time to be prepared by the blood bank. Massive transfusion can produce dilutional coagulopathy, hypocalcemia and hypomagnesemia. Blood-borne viral pathogens may be transfused, causing hepatitis or HIV.

Hemoglobin solutions: In an effort to satisfy the need for a nonantigenic, disease-free, oxygen-carrying fluid a number of hemoglobin solutions are now at advanced stages of development ${ }^{[9,10]}$ [Table 1]. Free hemoglobin causes severe renal injury. Polymerization of the hemoglobin overcomes this problem and improves intravascular persistence. Human hemoglobin-based preparations are naturally occurring and have been studied extensively; however, there is a limited availability of outdated units of blood that are needed for production. There are three main sources for the hemoglobin solutions currently under development: (a) bovine blood, (b) out-of-date human blood and (c) recombinant hemoglobin. The products currently under investigation do not require cross-matchings, have similar dissociation curve to blood and are apparently free from risk of transmitting viral or bacterial infections. They have an intravascular half-life of about 24h. Diaspirin cross-linked hemoglobin [DCLHb (Hem Assist, Baxter)] and bovine hemoglobin solution (Hemopure, Biopure) have a significant vasopressor effect, which is thought to result from scavenging endothelial nitric oxide. ${ }^{[10]}$

Albumin: Human albumin is a single polypeptide with a molecular weight of 65-69 kDa and a strong negative charge of minus 17..$^{[11]}$ It has transport functions, free radical scavenging and anticoagulant properties and may have a role in preserving microvascular integrity.

As a result of the manufacturing process, human albumin solution is generally considered to be free from any risk of transmitting infection. However, a single bottle of albumin represents exposure to many thousands of donors and, there is a concern about the theoretical risk of transmission of the prion causing new variant Creutzfeldt Jakob disease.

\begin{tabular}{|c|c|c|c|c|}
\hline Manufacturer & Product & Type of $\mathrm{Hb}$ & Adverse effects & Comments \\
\hline $\begin{array}{l}\text { Baxter } \\
\text { (Deerfield, IL) }\end{array}$ & $\begin{array}{c}\text { HemAssist } \\
\text { (Diaspirin cross-linked) }\end{array}$ & $\begin{array}{l}\text { Human outdated } \\
\text { blood }\end{array}$ & $\begin{array}{c}\text { Vas-Vasomotor tone } \\
\text { nitric oxide } \\
\text { scavenging }\end{array}$ & $\begin{array}{l}\text { Development } \\
\text { ceased }\end{array}$ \\
\hline $\begin{array}{l}\text { Northfield Lab. } \\
\text { (Evanstone, IL) }\end{array}$ & $\begin{array}{c}\text { PolyHeme } \\
\text { (Glutaraldehyde } \\
\text { polymerized) }\end{array}$ & Human & $\begin{array}{l}\text { Mild increases } \\
\text { in bilirubin }\end{array}$ & $\begin{array}{l}\text { Phase III } \\
\text { trials }\end{array}$ \\
\hline $\begin{array}{l}\text { Hemosol } \\
\text { (Etobicoke, } \\
\text { Ontario, Canada) }\end{array}$ & $\begin{array}{c}\text { HemoLink } \\
\text { (O-raffinose polymerized) }\end{array}$ & $\begin{array}{l}\text { Human Outdated } \\
\text { blood }\end{array}$ & $\begin{array}{l}\text { Mild } \\
\text { gastrointestinal } \\
\text { discomfort. }\end{array}$ & $\begin{array}{l}\text { Phase II } \\
\text { trials }\end{array}$ \\
\hline $\begin{array}{l}\text { Biopure } \\
\text { (Upjohn, } \\
\text { Cambridge, MA) }\end{array}$ & $\begin{array}{c}\text { Hemopure } \\
\text { (Glutaraldehyde } \\
\text { polymerized) }\end{array}$ & Bovine & $\begin{array}{l}\uparrow \text { SVR and PVR } \\
\downarrow \text { cardiac output }\end{array}$ & $\begin{array}{l}\text { Phase III } \\
\text { trials }\end{array}$ \\
\hline $\begin{array}{l}\text { Somatogen } \\
\text { (Boulder, CO) }\end{array}$ & $\begin{array}{l}\text { Optro } \\
\text { (Recombinantly } \\
\text { Cross-linked) }\end{array}$ & Recombinant & $\begin{array}{l}\text { Vasoconstriction } \\
\text { Gastrointestinal }\end{array}$ & $\begin{array}{l}\text { Phase I } \\
\text { trials } \\
\text { symptoms }\end{array}$ \\
\hline $\begin{array}{l}\text { SVR }=\text { Systemic } \\
\text { PVR }=\text { Pulmonary }\end{array}$ & $\begin{array}{l}\text { vascular resistance } \\
\text { vascular resistance }\end{array}$ & & & \\
\hline
\end{tabular}


Colloids: A colloid is a fluid, containing particles that are large enough to exert an oncotic pressure across the microvascular membrane. In comparison to the crystalloids, they have greater intravascular persistence. The duration of intravascular persistence depends on molecular size, shape and ionic charge. Albumin is the only colloid containing particles of uniform molecular weight (monodisperse). The other colloids are polymers and contain particles with a wide range of molecular weights. Albumin, dextran and blood are naturally occurring colloids. Semisynthetic colloids include modified gelatins, hydroxyethyl starch and hemoglobin solutions. A 1 liter infusion of dextran 70 causes a 790 $\mathrm{ml} / \mathrm{L}$ increase in plasma volume; $6 \%$ hetastarch, a 710 $\mathrm{ml} / \mathrm{L}$ increase; $5 \%$ albumin, a $490 \mathrm{ml} / \mathrm{L}$ increase; and physiologic salt solution, a $180 \mathrm{ml} / \mathrm{L}$ increase. ${ }^{[12]}$ Proponents of colloid tout the more rapid resuscitation and lower volume of fluid needed with colloid resuscitation. Serum protein levels are maintained at more normal levels; therefore, the peripheral edema, usually manifest after massive resuscitation, is avoided somewhat.

Crystalloids: A crystalloid is a solution of nonionic or ionic particles. The contents of a number of commonly used crystalloids are listed in Table 2. Most crystalloid intravenous fluids are isotonic with plasma. They do not contain larger oncotic particles and will, therefore, pass freely across the microvascular membrane. Their precise distribution will be determined by their sodium concentration. Solutions containing approximately isotonic concentrations of sodium $(0.9 \%$ saline, Ringers solution) will distribute rapidly across most of the extracellular space. Crystalloids containing less than isotonic concentrations of sodium will be increasingly distributed to the intracellular space. Dextrose $5 \%$ is distributed throughout the total body water and is ineffective for replacing intravascular fluid loss. Advantages of crystalloid use note the lesser cost of crystalloid compared with colloids, although larger volumes are needed to reach similar endpoints. In states of increased vascular permeability, colloids tend to leak into the extravascular space, which leads to increases in colloid oncotic pressure in the interstitium, potentially increasing total lung water and pulmonary dysfunction. ${ }^{[12]}$ This increased oncotic pressure also may hamper the mobilization of third space fluid. The major disadvantages of isotonic crystalloids are their limited ability to remain within the intravascular space. Lactated Ringer's solution by the end of a 1 liter infusion expands the intravascular compartment by only $194 \mathrm{ml}$, the remaining $80 \%$ of fluid is lost to the interstitial space. Generally, two to four times as much crystalloid as 5\% albumin or $6 \%$ hetastarch is required to achieve the same physiologic endpoints. ${ }^{[13]}$

Hypertonic saline solution: $7.5 \%$ sodium chloride has an osmolality of 2400 mOsm / L have been used successfully to hemorrhagic shock. Smaller volumes of hypertonic saline is required for similar effects $(4-5 \mathrm{ml} /$ $\mathrm{Kg}$ ), making it particularly attractive for use during prehospital resuscitation. ${ }^{[14]}$ It elevates mean arterial pressure and cardiac output. Moreover, it also increases renal, mesenteric, total splanchnic and coronary blood flow. The intravascular persistence of hypertonic saline can be extended by mixing it with a colloid. The commonest of these hypertonic- hyperoncotic solutions is hypertonic saline - dextran ( $\mathrm{HSD}$, typically $\mathrm{NaCl} 7.5 \%$ and dextran - 70, 6\%). ${ }^{[15]}$

The beneficial effects of hypertonic saline following controlled hemorrhage have been established. Using hypertonic saline during uncontrolled hemorrhage, however, has been strongly questioned.

\begin{tabular}{|c|c|c|c|c|c|c|c|c|}
\hline Component & NS $(0.9 \%)$ & LR & P-lyte & HS (3\%) & Albumin $(5 \%)$ & Hetastarch (6\%) & Dextran-70 (6\%) & Gelatins \\
\hline Sodium (mEq/L) & 154 & 130 & 140 & 513 & -145 & 154 & 154 & 145 \\
\hline Potassium (mEq/L) & 0 & 4 & 5 & 0 & 0 & 0 & 0 & 5.1 \\
\hline Chloride (mEq/L) & 154 & 109 & 98 & 513 & -145 & 154 & 154 & 145 \\
\hline Lactate $(\mathrm{mEq} / \mathrm{L})$ & 0 & 28 & 0 & 0 & 0 & 0 & 0 & 0 \\
\hline Calcium (mEq/L) & 0 & 2.7 & 0 & 0 & 0 & 0 & 0 & 0 \\
\hline Acetate $(\mathrm{mEq} / \mathrm{L})$ & 0 & 0 & 27 & 0 & 0 & 0 & 0 & 6.25 \\
\hline Gluconate $(\mathrm{mEq} / \mathrm{L})$ & 0 & 0 & 23 & 0 & 0 & 0 & 0 & 0 \\
\hline Magnesium (mEq/L) & 0 & 0 & 3 & 0 & 0 & 0 & 0 & 0 \\
\hline Osmolarity (mOsm/L) & 310 & 275 & 294 & 1025 & 310 & 310 & 310 & $\sim$ Isotonic \\
\hline Oncotic pressure (mmHg) & 0 & 0 & 0 & 0 & 20 & 30 & 60 & $\sim 35-39$ \\
\hline pH & 5.0 & 6.5 & 7.4 & 5.0 & 6.9 & 5.5 & $3-7$ & 7.3 \\
\hline
\end{tabular}

HS - hypertonic saline, LR - lactated Ringer's, NS - normal saline 


\section{Objectives of Fluid Replacement}

Severe hypovolemia is associated with cardiovascular decompensation, reduced cellular perfusion and oxygen delivery and the development of profound lactic acidosis. ${ }^{[16]}$ If oxygen delivery is not restored quickly, cell membrane pumps fail and cellular function will not recover even if adequate oxygen delivery is restored. Depending on the number of cells sustaining irreversible damage organ failure or death may ensure. Therefore, the rational behind fluid replacement in the trauma patient is to minimize the number of irreversibly damaged calls by restoring adequate tissue perfusion and oxygen delivery as rapidly as possible. ${ }^{[17]}$

\section{Vascular Access}

In trauma patients presenting with multiple injuries and hemorrhagic shock, vascular access is necessary. The urgency of the placement and the size and number of intravenous catheters are dictated by the degree of shock, the duration and the rate of bleeding and type of injury. Access to the vascular system must be obtained promptly. This is best done by the insertion of two largecaliber peripheral intravenous catheters before any consideration is given to a central venous line. The rate of flow is proportional to the fourth power of the radius of the catheter and the pressure gradient between the catheter opening and venous system and is inversely related to its length and fluid viscosity (Poiseuille's Law). Hence, short-length, large-caliber catheters are preferred for rapid infusion of large volumes of fluid.

Location of the injury must be considered when choosing a site for venous access. One should avoid venous access in injured limbs. In patients with injuries below the diaphragm, at least one intravenous catheter should be placed in the tributary of the superior vena cava because vascular disruption of the inferior vena cava may be present.

If circumstances prevent the use of peripheral veins, large-caliber, central venous (femoral, jugular or subclavian vein) access using the Seldinger technique or saphenous vein cutdown is indicated depending on the skill and experience level of the doctor. In children younger than six years, the placement of an intraosseous needle should be attempted before central line insertion. ${ }^{[18]}$

\section{When to Give Fluid}

Fluid administration is the cornerstone of acute resuscitation. Intravascular volume is lost because of hemorrhage, uptake by ischemic cells and extravasation into the interstitial space. Administration of intravenous fluids will predictably increase cardiac output and blood pressure in a hypovolemic trauma patient. ${ }^{[19]}$ Hence, it might seem logical to start rapid fluid infusion as soon as possible after trauma so that adequate perfusion is restored as quickly as possible. This implies starting fluid replacement at the scene. However, attempts to replace fluid may delay the patient's arrival in the hospital more than 30 minutes and leads to less chance of improvement in outcome in patients with severe trauma. Moreover, under some circumstances, increasing the patients blood pressure before control of hemorrhage may disrupt the hemostatic thrombus by increase in blood pressure, producing secondary hemorrhage. ${ }^{[20,21]}$

Animal experiments have demonstrated decreases in mortality when animals were resuscitated to a mean arterial pressure (MAP) of $40 \mathrm{~mm} \mathrm{Hg}$ versus those resuscitated to a more normal MAP. Animals resuscitated to the higher MAP had more blood loss and increased hemodilution. ${ }^{[22]}$ However, in the absence of radial pulse (or a central pulse for penetrating torso injuries), consideration should be given to administration of intravenous fluid en route to hospital. ${ }^{[23]}$

\section{Which Fluid for Volume Replacement?}

Once hemorrhage has been controlled, fluid resuscitation is important. Intravascular volume should be restored as quickly as possible in an effort to restore an adequate cardiac output and reverse tissue ischemia.

Despite the fact that most trauma patients presents the signs and symptoms of hypovolemia due to moderate-to-severe blood loss, packed red cells and blood derivatives are uncommonly transfused on the scene of the accident. It is important to carefully scrutinize the pros and cons associated with their use even in more advanced phases. ${ }^{[24,25]}$ Today, many different classes of fluids (other than blood and blood-derivatives) are available ${ }^{[26]}$ and their actions are best understood by examining the relationship between the fluids used in the resuscitation of trauma victims and the body's water compartments [Figure 1]. 


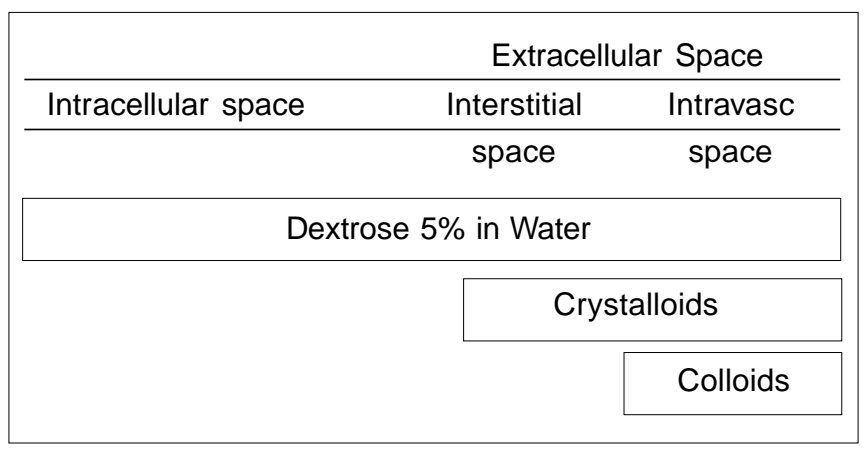

Figure 1: Distribution of body water and resuscitation fluids. Dextrose $5 \%$ in water freely permeates the whole water distribution space, whereas crystalloids and colloids have access only to the extracellular and intravascular spaces, respectively

Infusion of a balanced salt solution is the current standard of care with the initial bolus, as per Advanced Trauma Life Support guidelines, given "as rapidly as possible"- the usual dose is $1 \mathrm{~L}$ or $2 \mathrm{~L}$ for adults and 20 $\mathrm{ml} / \mathrm{Kg}$ for children. The main controversy surrounds which fluid or fluids are the most appropriate for achieving these goals.

Crystalloids versus colloids: There are no prospective randomized controlled trials with adequate power to detect a difference in survival as the primary endpoint. There is little doubt that, in comparison with colloid, larger volumes of crystalloid are required to restore intravascular volume. There is also generalized agreement that colloids, but not crystalloids, can cause anaphyllactoid reactions. Beyond these two facts, however, there would appear to be very little agreement.

The popular approach to fluid resuscitation of trauma patient is to use both crystalloid and colloid. After hemorrhage there will be some movement of interstitial fluid into the intravascular space ${ }^{[27]}$ while intracellular volume remains unchanged. ${ }^{[28]}$ The replacement of interstitial fluid as well as intravascular fluid would seem logical. However, patients with severe injuries will quickly develop systemic inflammatory response syndrome (SIRS) ${ }^{[29]}$ and with it, a leaky microcirculation. A significant proportion of any colloid solution will enter the interstitial space, the precise quantity being determined by the range of molecular size, molecular charge and extent of capillary leak. The better intravascular retention of colloids in comparison with crystalloid may make it easier to interpret the results of a colloid fluid challenge.

Colloids versus colloids: The wide-ranging pharmacological and pharmacodynamic properties of the colloids emphasize the significant differences between these fluids.

In patients without capillary leak, the gelatin solutions will exert a reasonable plasma oncotic pressure but, in comparison with other colloids, this effect is short-lived (about two hours).

Intravascular retention of dextran and hydroxyethyl starch (HES) is significantly better than gelatin. ${ }^{[30]}$ However, the potential for dextran and HES to impair coagulation limits their use for very high volume resuscitation. This problem limits the maximum safe dose of dextran to about $1500 \mathrm{ml}$ or $70 \mathrm{Kg}$ weight/day. Medium and low molecular weight HES has limited effect on coagulation than high molecular weight HES (450 / 0.7). However, it has been recommended to restrict its use to approximately $2 \mathrm{~L} /$ day in the average weight patient. There is some evidence that HES (200/0.5) may improve microcirculatory perfusion, possibly by reducing endothelial swelling or by modifying leukocyte adhesion. ${ }^{[31]}$ It may inhibit some components of acute inflammation ${ }^{[32]}$ but as yet the potential impact of this on outcome remains unclear. Most of these theoretical advantages have been attributed to dextran as well. ${ }^{[33]}$

Albumin is relatively expensive. There is no clear indication for its use in adult trauma resuscitation. It is still used by many pediatricians, partly because HES is not licensed for use in children. However, some authors have proposed banning or at least limiting the use of albumin in critically ill patients, pending the results of randomized, controlled trials. ${ }^{[34,35]}$

Hypertonic saline solutions: Hypertonic saline solutions are attractive as they provide small volume resuscitation and rapid restoration of hemodynamics with laboratory evidence of improved microcirculatory hemodynamics. ${ }^{[36]}$ However, the role of hypertonic saline solutions in trauma resuscitation has yet to be defined. The side-effects of hypertonic saline are related to their action and include hypernatremia, hyperchloremic metabolic acidosis and the risk of pulmonary edema, especially in patients with limited cardiac reserve. Another theoretical risk derives from an excessive increase of the volemia and / or arterial pressure, which could enhance bleeding. Hypertonic solutions require 
further clinical investigation and, as yet, are not in common use.

Hemoglobin solutions: In comparison with blood, hemoglobin solution may provide oxygen delivery to ischaemic tissue; the acellular fluid may perfuse capillaries that are compressed by edema that would prevent the passage of red cells and hemoglobin polymer is able to filter from the circulation. ${ }^{[11]}$ Advantages of hemoglobin solutions include longer self-life, lower cost, no need for cross-matching and minimal risk of viral transmission. Concerns with hemoglobin solution include the potential for inappropriate vasoconstriction and hypertension as a result of increased scavenging of nitric oxide and potentiation of coagulopathy because of platelet impairment. ${ }^{[19]}$ Although the long-term safety of massive transfusion with any of the hemoglobin solutions has yet to be demonstrated, it is highly likely that in the future at least one of these fluids will be a routine therapy for trauma patient resuscitation.

\section{Fluid Warming}

Fluid and blood resuscitation of trauma patient is best accomplished with large gauge intravenous catheters and effective fluid warmers with high thermal clearance. ${ }^{[37]}$ All intravenous fluids given to the injured patient should be prewarmed to $39^{\circ} \mathrm{C}\left(102.2^{\circ} \mathrm{F}\right)$ before using. The use of blood warmers is cumbersome yet most desirable in the emergency department. The most efficient way to warming the fluids is by storing crystalloids in warmer or with the use of a microwave oven. ${ }^{[38]}$ Blood products cannot be warmed in the microwave oven but can be heated with passage through intravenous fluid warmers. Hypothermia following a major trauma increase mortality ${ }^{[3]}$ and has a number of adverse effects: ${ }^{[40]}$

1. Oxyhemoglobin dissociation curve is shifted to the left which impairs peripheral oxygen unloading.

2. Shivering will compound the lactic acidosis that accompanies hypovolemia.

3. Hypothermia increases bleeding by dilutional coagulopathy. ${ }^{[41]}$

4. Hypothermia increases the risk of infection. ${ }^{[42]}$

5. Hypothermia increases the risk of cardiac morbid events. ${ }^{[43]}$

\section{Endpoints of Resuscitations}

The conventional endpoints - heart rate, blood pressure and urine output are crude assessment of the adequacy of resuscitation following severe trauma. ${ }^{[44,45]}$ Hypoperfusion can coexist with normotension until severe derangements occur, causing multiple organ dysfunction syndrome. Furthermore, it is unclear whether values of cardiac index, oxygen consumption and oxygen delivery are valid endpoints or markers of a preferred physiology associated with fewer complications and perhaps improved survival. The search has continued for valid markers of adequate resuscitation. ${ }^{[46,47]}$

1. Believe of many investigators that base deficit reflects the hemodynamic and tissue perfusion changes associated with hemorrhagic shock. ${ }^{[48]}$ Base deficit is extremely attractive, given the ease and the speed with which the analysis can be completed.

The base deficit reflects the severity of shock, the oxygen debt, changes in oxygen delivery, the adequacy of fluid resuscitation and the likelihood of multiple organ failure and survival with reasonable accuracy in previously healthy adult and pediatric trauma patients. ${ }^{[49-51]} \mathrm{A}$ base deficit between 2 and 5 $\mathrm{mmol} / \mathrm{L}$ suggest mild shock, between 4-14 mmol/L is a sign of severe shock. On admission base deficit in excess of 5 to $8 \mathrm{mmol} / \mathrm{L}$ correlates with increased mortality. ${ }^{[50,51]}$

2. Serum lactate determination is a reliable marker of hypoperfusion in hemorrhagic shock. ${ }^{[52]}$ Lactate levels are a measure of anaerobic metabolism secondary to inadequate $\mathrm{DO}_{2}$. The amount of lactate produced is believed to correlate with the total oxygen debt, the magnitude of hypoperfusion and thus, the severity of shock. Although initial lactate levels may not correlate with outcome, the ability to clear lactate to normal seems to predict adequate resuscitation. Serum lactate levels also can be followed as the resuscitation continues. The normal plasma lactate concentration is 0.5 to $1.5 \mathrm{mmol} / \mathrm{L}$; levels above 5 $\mathrm{mmol} / \mathrm{L}$ indicate significant lactic acidosis. The halflife of lactate is approximately $3 \mathrm{~h}$; thus the level decreases rather gradually after correction of the cause. Failure to clear lactate within 24 hours after circulatory shock is a predictor of increased mortality. ${ }^{[53]}$

3. Organ specific monitoring: It may be useful in ensuring adequate resuscitation. The splanchnic bed is a region that affected earliest by hypoperfusion. Therefore, measuring intramucosal (gastric mucosal) 
$\mathrm{pH}$ may allow more rapid identification of hypoperfusion. Sustained decrease in intracellular $\mathrm{pH}$ correlates with systemic and intraabdominal complications, such as intraabdominal abscesses, bacteremia and intraabdominal hypertension.

4. Sublingual capnometry is a noninvasive addition to organ perfusion monitoring. In trauma patients in the early phase of shock, it detected hemorrhage as accurately as base deficit and plasma lactate. ${ }^{[54]}$ The device consists of a sublingual $\mathrm{CO}_{2}$ sensor that directly measures mucosal $\mathrm{PCO}_{2}$. The normal value for $\mathrm{SLPCO}_{2}$ is 45 to $50 \mathrm{~mm} \mathrm{Hg}$; elevated levels suggest organ hypoperfusion.

\section{Recommendations}

Recommendations cover the management of adults, children and infants with physical injuries as a result of trauma, in whom there is evidence of obvious or probable blood loss.

- It is recommended that in the prehospital management of adults and older children, intravenous fluid should not be administered if a radial pulse can be felt (or, for penetrating torso injuries, if a central pulse can be felt).

- In the absence of a radial pulse (or, central pulse for penetrating torso injuries) in adults or older children, it is recommended that intravenous fluid should be administered in boluses of no more than $250 \mathrm{ml}$. The patient should then be reassessed and the process repeated until a radial pulse (or, central pulse for penetrating torso injuries) is palpable.

- The administration of intravenous fluid should not delay transportation to hospital but when given in accordance with the recommendation above, consideration should be given to administration en route to hospital.

- It is recommended that when intravenous fluid is indicated in the prehospital setting, crystalloid solutions should be the routine choice.

- Transfer to hospital should not be delayed by attempts to administer intravenous fluid.

- Fluid therapy should be titrated against response to guard against over resuscitation. Blood pressure targets could be established, that will maintain better systemic perfusion and reduce the risks of causing further hemorrhage (systolic blood pressure of $80 \mathrm{~mm}$ $\mathrm{Hg}$ is appropriate for tissue perfusion and minimizing hemorrhage) ${ }^{[55,56]}$

\section{Summary}

Fluid management in severely injured patients is a complicated issue and there are no high-ranked randomized, controlled trials that can help to classify the situation. Prehospital fluid replacement must not delay the patient's transfer to hospital. Once, hemorrhage is controlled, restoration of normovolemia is a priority. Initially, the precise fluid used is probably not important, as long as appropriate volume is given. Anemia is much better tolerated than hypovolemia. The crystalloid colloid debate continues but existing clinical practice is more likely to reflect local biases and dogma rather than evidence based medicine. Colloids vary substantially in their pharmacology and pharmacokinetics. In the presence of SIRS, when the microcirculation is 'leaky', there may be some advantages to high or medium weight colloids such as hydroxyethyl starch. At this stage, gelatins (smaller molecular weight colloid) offer little advantage over crystalloids. Hypertonic saline solutions may have some benefit in patients with head injuries.

Although transfusion therapy is an extremely important component of resuscitation for trauma patients, adherence to the indications for blood component therapy is necessary because of the potential adverse effects and cost of transfusion therapy. A number of hemoglobin solutions are under development. It is highly likely that at least one of these solutions will eventually become routine therapy for trauma patient resuscitation.

\section{References}

1. Sauaia A, Moore FA, Moore EE, Moser KS, Brennan R, Read $\mathrm{RA}$, et al. Epidemiology of trauma deaths: A reassessment. $J$ Trauma 1995;38:185-93.

2. Acosta JA, Yang JC, Winchell RJ, Simons RK, Fortlage DA, Hollingsworth-Fridlund $P$, et al. Lethal injuries and time to death in a level 1 trauma centre. J Am Coll Surg 1998;186:528-33.

3. Talving P, Palstedt J, Riddez L. Prehospital management and fluid resuscitation in hypotensive trauma patients admitted to Karolinska University hospital in Stockholm. Prehosp Disast Med 2005;20:228-34.

4. Gillham MJ, Parr MJ. Resuscitation for major trauma. Curr Opin Anaesthesiol 2002;15:167-72.

5. Blalock A. Acute circulatory failure as exemplified by shock and hemorrhage. Sur Gynecol Obstet 1934;58:551-6.

6. Cannon W, Fraser J, Cowell E. Preventive treatment of wound shock. JAMA 1918;70:618-21. 
7. Keel M, Trenta O. Pathophysiology of polytrauma. Injury 2005;36:691-709.

8. Shires GT, Barber AE, Ilner HP. Current status of resuscitation: Solutions including hypertonic saline. Adv Surg 1995;28:133-70.

9. Cohn SM. Is blood obsolete? J Trauma 1997;42:730-2.

10. Conhaim RL, Harms BA. Hemoglobin therapeutics in hemorrhagic shock. Curr Opin Crit Care 1998;4:422-6.

11. Margarson MP, Soni N. Serum albumin: Touchstone or totem? Anaesthesia 1998;53:789-803.

12. Haupt MT, Kaufman BS, Carlson RW. Fluid resuscitation in patients with increased vascular permeability. Crit Care Clin 1992;8:341-53.

13. Dutton RP. Fluid management in the trauma patient. Crit Care Pain 2006;6:144-7.

14. Cooper DJ, Myles PS, McDermott FT, Murray LJ, Laidlaw J, Cooper G, et al. Prehospital hypertonic saline resuscitation of patients with hypotention and severe traumatic brain injury. JAMA 2004;291:1350-7.

15. Riddez L, Drobin D, Sjostrand F, Svensen C, Hahn RG. Lower dose of hypertonic saline dextran reduces the risk of lethal rebleeding in uncontrolled hemorrhage. Shock 2002;17:377-82.

16. Dunham CM, Siegel JH, Weireter L, Fabian M, Goodarzi S, Guadalupi $\mathrm{P}$, et al. Oxygen debt and metabolic acidaemia as quantitive predictors of mortality and the severity of the ischaemic insult in haemorrhagic shock. Crit Care Med 1991;19:231-43.

17. Chiara O, Scott JD, Cimbanassi S, Marini A, Zoia R, Rodriguez $A$, et al. Trauma deaths in an Italian urban area: An audit of prehospital and in-hospital trauma care. Injury 2002;33:553-62.

18. American Heart Association and American Academy of Pediatrics: Intraosseous infusion. In: Chameides L, editor. Textbook of Pediatric Advanced Life Support. American Heart Association: Dallas; 1988. p. 43-4.

19. Dutton RP, McCunn M. Anesthesia for trauma. In: Miller ER, editor. Miller's Anesthesia. $6^{\text {th }}$ ed. Elsevier Churchill Livingstone: Philadelphia; 2005. p. 2459-69.

20. Bickell WH, Wall MJ, Pepe PE, Martin RR, Ginger VF, Allen MK, et al. Immediate versus delayed fluid resuscitation for hypotensive patients with penetrating torso injuries. N Engl J Med 1994;331:1105-9.

21. Lepaniemi A, Soltero R, Burris D, Pikoulis E, Waasdorp C, Ratigan $\mathrm{J}$, et al. Fluid resuscitation in a model of uncontrolled haemorrhage: Too much too early or too little too late ? J Surg Res 1996;63:413-8.

22. Kowalenko T, Stern S, Dronen S, Wang X. Improved outcome with hypotensive resuscitation of uncontrolled hemorrhagic shock in a swine model. J trauma 1992;33:349-53.

23. National Institute of Clinical Excellence (NICE). Pre-hospital initiation of fluid replacement therapy in trauma. London, UK;
2004. p. 74-78.

24. Sclea TM, Holman M, Fuortes M, Baron BJ, Phillips TF, Goldstein $A S$, et al. Central venous blood oxygen saturation: An early, accurate measurement of volume during hemorrhage. J Trauma 1988;28:725-32.

25. Mikulaschek A, Henry SM, Donovan R, Scalea TM. Serum lactate is not predicted by anion gap or base excess after trauma resuscitation. J Trauma 1996;40:218-24.

26. Bilkowsi RN, Rivers EP, Horts HM. Targeted resuscitation strategies after injury. Curr Opin Crit Care 2004;10:529-38.

27. Tisherman SA, Barie P, Bokhari F, Bonadies J, Daley B, Diebel $\mathrm{L}$, et al. Clinical practice guidelines: Endpoints of resuscitation. $\mathrm{J}$ Trauma 2004;57:898-912.

28. Davis JW, Shackford SR, Holbrook TL. Base deficit as a sensitive indicator of compensated shock and tissue oxygen utilization. Surg Gynecol Obstet 1991;173:473-6

29. Eberhard LW, Morabito DJ, Matthay MA, Mackersie RC, Campbell AR, Marks JD, et al. Initial severity of metabolic acidosis predicts the development of acute lung injury in severely traumatized patients. Crit Care Med 2000;28:125-31.

30. Peterson DL, Schinco MA, Kerwin AJ, Griffen MM, Pieper P, Tepas $\mathrm{JJ}$. Evaluation of initial base deficit as a prognosticator of outcome in the pediatric trauma population. Am Surg 2004;70:326-32.

31. Randolph LC, Takacs M, Davis KA. Resuscitation in the pediatric trauma population: Admission base deficit remains an important prognostic indicator. J Trauma 2002;53:838-42.

32. Vitek V, Cowley RA. Blood lactate in the prognosis of various forms of shock. Ann Surg 1971;173:308-13.

33. Caplan LM, Miller SM. Trauma and burns. In: Barash PG, Cullen BF, Stoelting RK, editors. Clinical Anesthesia. $5^{\text {th }}$ ed. Lippincott Williams and Wilkins: Philadelphia; 2006. p. 1262-97.

34. Baron BJ, Sinert R, Zehtabchi S, Stavile KL, Scalea TM. Diagnostic utility of sublingual PCO2 for detecting hemorrhage in penetrating trauma patients. J Trauma 2004;57:69-74.

35. Madjdpour C, Spahn DR. Allogenic red blood cell transfusions: Efficacy, risks, alternatives and indications. $\mathrm{Br} \mathrm{J}$ Anaesth 2005;95:33-42.

36. Spahn SR, Raissaint R. Coagulopathy and blood component transfusion in trauma. Br J Anaesth 2005;95:130-9.

37. Boldt J. Fluid choice for resuscitation of the trauma patient: $A$ review of the physiological, pharmacological and clinical evidence. Can J Anaesth 2004;51:500-13.

38. Drobin D, Hahn RG. Volume kinetics of Ringer's solution in hypovolaemic volunteers. Anesthesiology 1999;90:81-91.

39. Bock JC, Barker BC, Clinton AG, Wilson MB, Lewis FR. Posttraumatic changes in and effect of colloid osmotic pressure on the distribution of body water. Ann Surg 1989;210:395-405.

40. Muckart DJ, Bhagwanjee S. American College of Chest 
Physicians/ Society of Critical Care Medicine Consensus Conference definitions of the systemic inflammatory response syndrome and allied disorders in relation to critically injured patients. Crit Care Med 1997;25:1789-95.

41. American Thoracic Society. Evidence-based colloid use in the critically ill: American Thoracic Society Consensus Statement. Am J Resp Crit Care Med 2004;170:1247-59.

42. Boldt J, Heesen M, Muller M, Pabsdorf M, Hempelmann G. The effects of albumin versus hydroxyethyl starch solution on cardiorespiratory and circulatory variables in critically ill patients. Anesth Analg 1996;83:254-61.

43. Schmand JF, Ayala A, Morrison MH, Chaudry IH. Effects of hydroxyethyl starch after trauma haemorrhagic shock: Restoration of macrophage integrity and prevention of increasing circulating interleukin-6 levels. Crit Care Med 1995;23:806-14.

44. Haljamae H, Dahlquist M, Walentin F. Artificial colloids in clinical practice: Pros and cons. Bailliere's Clin Anaesth 1997;11:49-79.

45. Boldt J. The good, the bad and the ugly: Should we completely banish human albumin from our ICUs? Anesth Analg 2000;91:887-95.

46. Finfer S, Bellomo R, Boyce N, French J, Myburgh J, Norton R, et al. A comparison of albumin and saline for fluid resuscitation in the intensive care unit. N Engl J Med 2004;350:2247-56.

47. Rocha E, Silva M. Hypertonic Saline resuscitation: A new concept. Bailliere's Clin Anaesth 1997;11:127-42.

48. Smith CE. Current practices in fluid and blood component therapy in trauma. In: Massive transfusion and control of hemorrhage in the trauma patient (accreditation council for containing medical education, ITACCS). 2003. p. 18-22.

49. Werwath DJ, Schwab CW, Scholter JR. Microwave oven: A safe new method of warming crystalloids. Am J Surg 1984;12:656-9.

50. Gentilello LM, Jurkovich GJ, Stark MS, Hassantash SA, O'Keefe GE. Is hypothermia in the victim of major trauma protective or harmful? A randomized, prospective study. Ann Surg 1997;226:439-49.

51. Sessler DI. Mild perioperative hypothermia. N Engl J Med 1997;336:1730-7.

52. Schmied H, Kurz A, Sessler DI, Kozek S, Reiter A. Mild hypothermia increases blood loss and transfusion requirements during hip arthroscopy. Lancet 1996;347:289-92.

53. Kurz A, Sessler DI, Lenhardt R. Perioperative normothermia to reduce the incidence of surgical wound infection and shorten hospitalization. N Engl J Med 1996;334:1209-15.

54. Frank SM, Fleisher LA, Breslow MJ, Higgins MS, Olson KF, Kelly $S$, et al. Perioperative maintenance of normothermia reduces the incidence of morbid cardiac events. JAMA 1997;277:1127-34.

55. Dahan E, Orbach S, Weiss YG. Fluid management in trauma. Int Anesthesiol Clin 2003;38:141-8.

56. Tisherman SA. Regardless of origin, uncontrolled haemorrhage is uncontrolled haemorrhage. Crit Care Med 2000;28:892-4.
Source of Support: Nil, Conflict of Interest: None declared.

\section{Author Help: Online Submission of the Manuscripts}

Articles can be submitted online from http://www.journalonweb.com. For online submission articles should be prepared in two files (first page file and article file). Images should be submitted separately.

1) First Page File:

Prepare the title page, covering letter, acknowledgement, etc., using a word processor program. All information which can reveal your identity should be here. Use text/rtf/doc/pdf files. Do not zip the files.

2) Article file:

The main text of the article, beginning from Abstract till References (including tables) should be in this file. Do not include any information (such as acknowledgement, your names in page headers, etc.) in this file. Use text/rtf/doc/pdf files. Do not zip the files. Limit the file size to $400 \mathrm{~kb}$. Do not incorporate images in the file. If file size is large, graphs can be submitted as images separately without incorporating them in the article file to reduce the size of the file.

3) Images:

Submit good quality colour images. Each image should be less than $\mathbf{1 0 0} \mathbf{k b}$ in size. Size of the image can be reduced by decreasing the actual height and width of the images (keep up to about 3 inches) or by reducing the quality of image. All image formats (jpeg, tiff, gif, bmp, png, eps, etc.) are acceptable; jpeg is most suitable. The image quality should be good enough to judge the scientific value of the image.

Always retain a good quality, high resolution image for print purpose. This high resolution image should be sent to the editorial office at the time of sending a revised article.

4) Legends:

Legends for the figures/images should be included at the end of the article file. 